\title{
INDEX OF INVITED REVIEWS
}

Gullis, C. A. (Norwich). Molecular aspects of the environmental induction of heritable changes in flax

Pukkila, P. J. (Mill Hill). Biochemical analysis of genetic recombination in eukaryotes

Auerbach, G. (Edinburgh). (Mendel Lecture.) Forty years of mutation research: a pilgrim's progress

Volume Page

$38 / 2 \quad 129-154$

$39 / 2 \quad 193-218$

$40 / 2 \quad 177-188$

Eaves, L. J., Last, K. A., Young, P. A. and Martin, N. G. (Birmingham). Model-fitting approaches to the analysis of human behaviour

$41 / 3 \quad 249-320$

Cove, D. J. (Leeds). The uses of isolated protoplasts in plant genetics

$43 / 3 \quad 295-314$

MACGREGOR, H. C. (Leicester). Recent developments in the study of lampbrush chromosomes 